\title{
Studies on the Artificial Rearing of Mole Cricket, Gryllotalpa orientalis (Orthoptera : Gryllotalpidae)
}

\author{
Young-Kyu Park ${ }^{1, *}$ and Young-Bo Lee ${ }^{2}$ \\ ${ }^{1}$ Korea Beneficial Insects Lab. Co. Ltd., Jangam-ri, Iljuk-myeon 236, Anseong-si Gyeonggi-do 456-910, Republic of Korea \\ ${ }^{2}$ Applied Entomology Division, National Academy of Agricultural Science, RDA, Suwon 441-100, Republic of Korea
}

(Received 28 November 2012; Accepted 27 December 2012)

The present study is to develop the rearing method of Gryllotalpa orientalis. In total 429 of G. orientalis were collected from the field rearing cage $\left(25 \mathrm{~m}^{2}\right)$ in 2012. Its sex ratio was 1: 1.15 (Female : Male). Survival rate of the mole crickets was $94.4 \sim 86.1 \%$ with the artificial diets formulated for the present study. Successful oviposition rate was 20,20 and $80 \%$ for one, two and three pairs of adult crickets, respectively, from the indoor rearing. The mean number of hatchlings was $11.8 \pm 21.7,15.7 \pm 26.4$ and $25.8 \pm 38.8$, and the mean number of dead hatchlings 1.2, 1.7 and 1.2. The mortality of nymphs on horticultural soil and clay sand mixed with ocher was 18.3 and $10.0 \%$, respectively. The mortality of nymphs in circular and rectangular cages was, respectively, 60 and $40 \%$.

Key words: Gryllotalpa orientalis, Artificial rearing, Artificial diet, Oviposition, Hatch rate, Mortality, Rearing container

\section{Introduction}

Gryllotalpa orientalis (Brumeister) is a species of mole cricket, commonly known as the oriental mole cricket, in Gryllotalpidae (Orthoptera). It is found from Korea, Japan, China, Taiwan and Philippine and widely known as an agricultural insect pest inflicting damage on roots of various crops. In Korea it is known as a notorious insect pest of ginseng. There were several studies on oviposition

*To whom the correspondence addressed

Korea Beneficial Insects Lab. Co. Ltd(KBIL), Jangam-ri, Iljuk-myeon 236, Anseong-si Gyeonggi-do 456-910, Republic of Korea.

Tel: +82-61-362-8205; Fax: +82-61-362-8245

E-mail: entomo@kbil.co.kr

http://dx.doi.org/10.7852/ijie.2012.25.2.175 behaviour and rate, flight, seasonal fluctuation, emergence, etc (Kim et al., 1989; Kim, 1995). On the other hand, this cricket was used as remedy to treat inflammation such as thyroiditis and tonsilitis in the past, and it also has some medical properties such as antioxidant activity and antihistamines (Heo et al., 2008). Population of the species decreased drastically in South Korea during the last few decades so that Seoul city has initiated a protection project since 2000. Along with the project, the cricket has currently been considered not only as an insect pest but also a valuable insect resource (Choi et al., 2002; Park, 2005). Even though industrialization of the cricket has been hindered because of paucity of biological and ecological traits for mass rearing. It is important for insect industrialization to develop not only artificial rearing technique using natural and artificial diets but also mass rearing system. Kim et al. (2005) reported a successful artificial rearing of a different cricket species, but no study was made for the artificial rearing of G. orientalis until recent years. Lee (2008) and Bang et al. (2009) made some experiments on effectiveness of artificial diets for the mole cricket and other orthopteran insects. The aim of the present study is to provide vital information through indoor mass rearing using both artificial and natural diets in order to develop a mass rearing technique.

\section{Materials and Methods}

\section{Target insect and collection}

The target insect of the present study is G. orientalis, known as the oriental mole cricket. The crickets used for the experiments were collected with using light traps (200 W mercury arc lamp) and under street lights located near meadow, farms and residential areas. In 2011, the crickets were collected from a farm located in Ip-myeon, Gokseong-gun, Jeolanam-do, Korea (N35 ${ }^{\circ}$ 17' 49.69" 
Table 1. Number of collected G. orientalis, including adults and nymphs, and sex ratio

\begin{tabular}{cccc}
\hline & \multicolumn{2}{c}{ Number of catches } \\
\cline { 3 - 4 } & & $\begin{array}{c}\text { 14. May-21. } \\
\text { June, 2012 }\end{array}$ & $\begin{array}{c}\text { 10. Septem- } \\
\text { ber, 2012 }\end{array}$ \\
\hline \multirow{2}{*}{ Nymphs } & 1 3rd instar & 131 & 166 \\
& 3rd $\sim$ instar & & 44 \\
Adults & 57 & 31 \\
Sex ratio(female : male) & $1: 1.15$ & \\
\hline
\end{tabular}

${ }^{1}$ collected from hideouts in the field collection site

${ }^{2}$ collected from the outdoor rearing cage $\left(6 \mathrm{~m}^{2}\right)$

Table 2. The compositions of nutrients in the artificial diets formulated with the powder of house fly puparia for the laboratory rearing of $G$. orientalits

\begin{tabular}{ccccc}
\hline \multirow{2}{*}{ Ingredients } & \multicolumn{4}{c}{ Types of formulae (\%) } \\
\cline { 2 - 5 } & $\mathrm{A}$ & $\mathrm{B}$ & $\mathrm{C}$ & $\mathrm{D}$ \\
\hline Agar & & & & \\
Wheat germ & 51.8 & 58.4 & 62.1 & 66.1 \\
Insect pupa & 20.7 & 10.5 & 5.0 & 0 \\
Casein & 14.5 & 16.4 & 17.4 & 18.4 \\
Salt Mix. & 4.7 & 5.3 & 5.6 & 5.9 \\
Sorbic acid & 1.6 & 1.8 & 1.9 & 1.5 \\
Methyl Paraben & 1.0 & 1.2 & 1.2 & 0.7 \\
Vitamin Mix. & 5.7 & 6.4 & 6.8 & 7.4 \\
Ferric Citrate & 0.1 & 0.1 & 0.1 & 0.1 \\
Total & 100 & 100 & 100 & 100 \\
\hline
\end{tabular}

${ }^{1}$ the same amount (agar $16 \mathrm{~g}$, distilled water 1,000ml) was used in all of the four formulae

E127 $\left.12^{\prime} 14.87^{\prime \prime}\right)$. The collection started from the sun set till 11 PM. In 2012, nymphs and adults reared in an outdoor rearing cage were randomly selected for the experiments. In total about 1,000 crickets, collected from April, 2010 to September, 2012, were used for mass rearing experiments. The gender of the collected crickets was determined by the differences of the wing veins. During the experiments, artificial (formulated during the present study, see below) and natural diets (earth worms and vegetables such as potatoes and carrots) were provided.

\section{Development of artificial diet}

Four types of the artificial diet were formulated in different proportions of ingredients to test the mortality of the cricket during the rearing (Table 2). Among the ingredients house fly puparia (reared at Korea Beneficial Insects Lab.) were used as a protein source instead of the fish powder. The basic formula of the artificial diet is as follows: $16 \mathrm{~g}$ of agar was added in $1.5 \mathrm{~L}$ distilled water and boiled twice. The boiled agar solution was mixed in a blender with $100 \mathrm{~g}$ of wheat germs (Sigma), $28 \mathrm{~g}$ casein (Samcheon Chem.), $9 \mathrm{~g}$ Wesson's salt mix (Sigma), $3 \mathrm{~g}$ sorbic acid and $2 \mathrm{~g}$ Methyl-4-hydroxybenzoate (Sigma). $11 \mathrm{~g}$ of Vanderzant vitamin mixture (Sigma) and $0.1 \mathrm{~g}$ Ferric citrate (Sigma) were added and mixed in the last step. After blending all the ingredients above, the artificial diet solution was poured into petri-dishes $(90 \times 15 \mathrm{~mm}$, SPL life Science). The petri-dishes were left on benches until cooled and turned solid. The diet containers were sealed tight and kept at $2^{\circ} \mathrm{C}$ in a refrigerator.

\section{Selection of instar nymph}

The $2^{\text {nd }}$ instar nymphs were selected to prevent such unwanted mortality and reared in the petri-dishes $(100 \times$ $40 \mathrm{~mm}$, SPL life science) during the experiments.

\section{Oviposition rate and nymph mortality in indoor rearing cages}

To assess the oviposition rate in the artificial rearing condition one-, two- and three pairs of male and female were selected. Each set of pairs was released in a circular cage (Ø17 cm, height $25 \mathrm{~cm}$, volume $5 \mathrm{~L}$ ) that was filled with a 1:1 mixture of yellow ocher and horticultural soil(Punong Co.). After the ovipoistion counting for egg numbers and mortality were made two months later to prevent unwanted death of the eggs and hatchlings.

\section{Mortality by different types of rearing soil substrata}

Two different rearing soil substrata were prepared: one only with general horticultural soil (Punong Co.) and the other mixture of yellow ocher and clay sand, which were gathered from $2 \mathrm{~m}$ deep subsoil in a ginseng farm.

\section{Mortality by different shapes of rearing cage}

To assess the influence of cage shapes on nymph mortality ten of $2^{\text {nd }}$ and $3^{\text {rd }}$ instar nymphs were released and reared in each of a circular $(\varnothing 17 \mathrm{~cm}$, height $25 \mathrm{~cm}$, volume $5 \mathrm{~L})$ and rectangular cage $(22 \times 17 \times 7 \mathrm{~cm})$. After 40 days the number of dead nymphs were counted. The rearing soil substratum used was a 1:1 mixture of the horticultural soil and yellow ocher.

\section{Results and Discussion}

\section{Collection from an outdoor rearing garden}

An outdoor rearing garden $\left(25 \mathrm{~m}^{2}\right)$ was built to attract the oriental mole crickets and settle in. It was filled with the horticultural soil, saw dust and organic garden composts. From May, 2012 many mole crickets were found to inhabit the garden. On the contrary, none of crickets was 


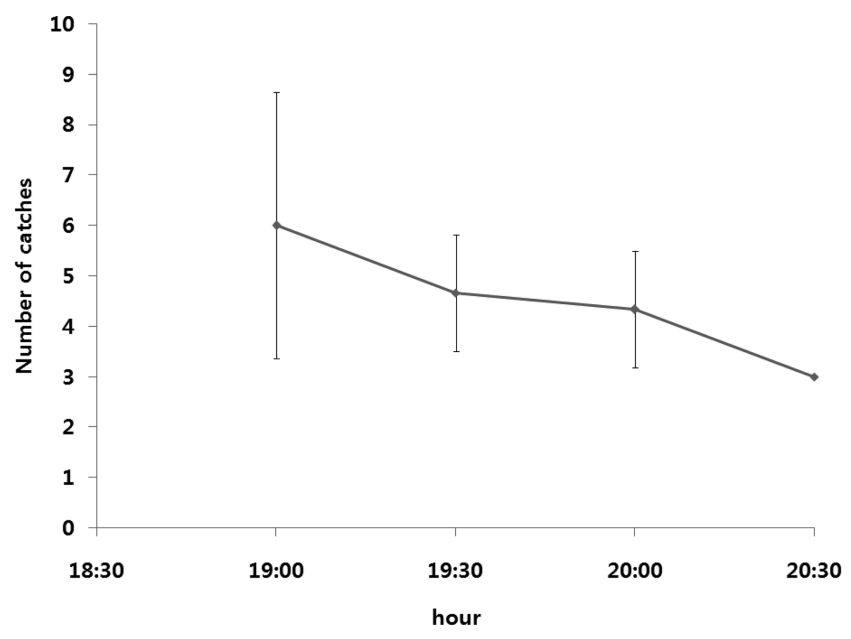

Fig. 1. Number of $G$. orientalis adults attracted by a light trap (200 W mercury arc lamp) from 19:00 to 21:00 hour during September(2012).

collected from the light traps during the same period.

In total 429 crickets were collected during the collection periods, and the sex ratio was $1: 1.15(\mathrm{~F}: \mathrm{M})$. From $14^{\text {th }}$ of May to $21^{\text {st }}$ of June, 188 individuals were collected in total, consisting of 131 nymphs and 57 adults. On $10^{\text {th }}$ of September, $40.2 \pm 12.3$ individuals $/ 1 \mathrm{~m}^{2}$ and 241 in total were collected. About $87.1 \%$ of them was nymphs, suggesting that the number of adults decreased after oviposition and the next generation started to grow up (Table 1). The collection results of the present study was similar with that of Kim et al. (1989) who reported that the highest number of the catches from May to June and the existence of mixed developmental stages of different generations in a year.

During the collection, adult and immature crickets were found crawling actively about hideouts or open space. We developed a new collection method using this trait: place stones or wood piece on the ground and 3 4 hours later collect crickets from their underground hideouts beneath the stones or wood pieces placed previously. The garden bed for the outdoor rearing was about $50 \sim 100 \mathrm{~cm}$ in depth and mainly made of the general horticultural soil. In the substratum of the garden not only the crickets but also various soil invertebrates such as earth worms and ground beetles were found inhabiting the garden bed.

\section{Night collections using the light traps}

The light traps ( $200 \mathrm{~W}$ mercury arc lamp) was used to lure and collect the crickets during nights. The results showed that the mean number of the catches from 19:00 to 20:30 hour was 6 , and the number decreased to $4,7,4,3$ and 3 every 30 minutes (Fig. 1). The collection results of 2011 were that the highest record was 73 and daily mean
Table 3. Comparison of the mortality of G. orientalis nymphal stages reared on the artificial and natural diets (at 27 $\left.\pm 2{ }^{\circ} \mathrm{C}\right)$

\begin{tabular}{|c|c|c|c|c|}
\hline \multirow{2}{*}{ Exp. $\left(n^{*}\right)$} & \multicolumn{4}{|c|}{ Mortality (\%) } \\
\hline & $2 \mathrm{nd}$ & $3 \mathrm{rd} \sim 4$ th & 4 th $\sim 8$ th & total \\
\hline A (54) & 0 & 18.5 & 7.4 & $12.9 \mathrm{a}^{* *}$ \\
\hline B (36) & 0 & 18.5 & 0 & $13.9 \mathrm{a}$ \\
\hline $\mathrm{C}(54)$ & 0 & 14.8 & 7.4 & $11.1 \mathrm{a}$ \\
\hline $\mathrm{D}(36)$ & 0 & 7.4 & 0 & $5.6 \mathrm{a}$ \\
\hline Natural $\operatorname{diet}^{\mathrm{a}}(36)$ & 0 & 81.5 & 11.1 & $63.9 \mathrm{~b}$ \\
\hline
\end{tabular}

a control: reared on earthworms from the 1st to 4th nymphal instars and addition of vegetables after 4th nymphal instar. ${ }^{*} \mathrm{n}$ : No. of nymphs examined.

${ }^{* *}$ Means followed by the same letter are not significantly different $(\mathrm{P}<0.05$; chi square test $)$

catches 32.7 individuals. Such difference between two years might have been caused by night temperature difference that might be closely related to activity of the crickets during night period.

\section{Formulation of the artificial diets}

Most of insect artificial diets have been developed for moth rearing. The formulae for the gypsy moth was referred to develop the diet for the oriental mole cricket. Some orthopetran insects including G. orientalis are omnivorous. Thus, we also referred to few studies using artificial diet with protein source and wheat germs to rear some orthopteran insects (Kim et al., 2005; Bang et al., 2009; Lee, 2008).

According to the formulae above, the artificial diet for the mole cricket was modified and formulated adding casein and powder of house fly puparia as protein sources (Table 2). The results of the different diet feeding tests did not show any significant difference on nymph mortality.

The mortality of the nymphs fed on natural diets was $63.9 \%$, the highest among the tests. The mortality of the nymphs fed with the diets with house fly powder ranged from 11.1 to $12.9 \%$, which was about two times higher than that of without the fly powder (Table 3). Thus, the artificial diet without the fly powder was considered to be suitable for artificial rearing.

The mole cricket was known to have high mortality when artificially reared. Lee (2008) reported that only $35 \sim 39 \%$ of the crickets survived through the whole developmental stages. The result of the present study showed very high survival rate, $89.1 \%$. It may be due to differences in the artificial diets and rearing method. The artificial diet formulated from the present study can be used widely for mass rearing of the crickets. 
Table 4. Oviposition rate, hatching rate and nymphal mortality of $G$. orientalis in the circular cage $(\varnothing 17 \times$ height $25 \mathrm{~cm}, 5 \mathrm{~L})$

\begin{tabular}{cccc}
\hline $\begin{array}{c}\text { pair of } G . \\
\text { orientalis }\end{array}$ & $\begin{array}{c}\text { Successful } \\
\text { oviposition } \\
\text { rate(\%) }\end{array}$ & $\begin{array}{c}\text { Mean no. of } \\
\text { hatchlings } \\
\text { (Min. } \sim \text { Max.) }\end{array}$ & $\begin{array}{c}\text { Mean no. of } \\
\text { dead nymphs }\end{array}$ \\
\hline 1 & 20 & $11.8 \pm 21.7(0 \sim 50)$ & $1.2 \pm 1.8$ \\
2 & 20 & $15.75 \pm 26.4(0 \sim 55)$ & $1.8 \pm 2.9$ \\
3 & 40 & $25.8 \pm 38.8(0 \sim 93)$ & $1.2 \pm 1.3$ \\
\hline
\end{tabular}

counted 60 days later after the initiation of the test

Compared to the result of the artificial diet tests, the mortality was $61.6 \%$ from the $3^{\text {rd }}$ and $4^{\text {th }}$ instar nymphs provided with earth worms. The nymphs after the $4^{\text {th }}$ instar were provided with vegetables together, and the mortality decreased to $0 \sim 2.8 \%$ (Table 4). Lastly, the cricket nymphs on the artificial diets showed mean mortality $10.9 \%$, which was significantly lower than that on natural diets. From the result the newly developed diet appears to be suitable for the cricket rearing.

\section{Oviposition rate and nymph mortality in indoor rearing cages}

The oriental mole cricket lays eggs in egg chambers hollowed out in the soil, and the mean number of eggs per chamber was 46 55.2 (Kim, 1995; Lee, 2008). The successful oviposition rate was not higher than $50 \%$ through the rearing of the present study: less than $20 \%$ with one and two pair of adult crickets and about $40 \%$ three pairs. In all the control and test groups, the mean number of hatchlings were only $11.8 \sim 25.8$, which was much less than the number of eggs deposited. The number of hatchlings from the three pairs above was 93, 55 from the two pairs and 50 the one pair. It appears that the number of hatchlings would get higher when more pairs are added and more eggs laid in the rearing cage. There is one thing to be noted. In 2011, it was found that the mortality of the eggs and hatchlings got significantly higher when they were disturbed by moving or touching. Thus, to prevent such unwanted deaths we did not take any risk to count them for two months after oviposition. It appears that the crickets can be reared in a relatively small space (5 liter size). This shows a good possibility for successful artificial rearing.

\section{Mortality by different types of rearing soil substrata}

When the horticultural soil was used without sterilization, various soil invertebrates such as Collemboras and mites were found from the soil. The natural habitats of the mole cricket is known to contain high humidity. During the first month testing the two different types of the soil substrata, none of the crickets in the cages died. However, the mean mortality on the horticultural soil bed was $18.3 \%$ and $10 \%$
Table 5. Mortality of G. orientalis nymphs by two different types of the rearing garden bed in the rectangular cage $(22 \times$ $17 \times 7 \mathrm{~cm})$

\begin{tabular}{cc}
\hline & Nymphal mortality $(\%)^{\mathrm{a}}$ \\
\hline Genera horticultural soil & 18.3 \\
Clay sand-ocher mix. & 10.0 \\
\hline${ }^{\mathrm{a}}$ counted 30 days later after the initiation of the test
\end{tabular}

Table 6. Survival rate of the $5^{\text {th }}$ and $6^{\text {th }}$ nymphs of G. orientalis in two different types of the cage

\begin{tabular}{lccc}
\hline \multirow{2}{*}{ Survival rate } & \multicolumn{2}{c}{ No. of nymphs/cage } \\
\cline { 3 - 4 } & & 5 & 10 \\
\hline \multirow{2}{*}{ Circular cage $^{\mathrm{a}}$} & $20 \%$ & $40 \%$ \\
& Rectangular cage & $60 \%$ & $60 \%$ \\
\hline
\end{tabular}

${ }^{a}$ counted 40 days later after the initiation of the test

${ }^{\mathrm{b}}$ cage size : Ø $17 \times$ height $25 \mathrm{~cm}, 5 \mathrm{~L}$

${ }^{\mathrm{c}}$ cage size : $22 \times 17 \times 7 \mathrm{~cm}$

on the clay sand-ocher mixture (Table 5). The clay sand consists of $0.01 \sim 0.05 \mathrm{~mm}$ sand grains, and the ocher contains hardly any nutrients. Thus, the mixture of these two soils appears to be unsuitable for growth of other soil invertebrates so that it is more suitable for the cricket rearing.

\section{Mortality by different shapes of rearing cage}

The result of the mortality comparison using different shapes of the cage was as follows: in the first set with 5 crickets added, $20 \%$ of the crickets survived in the circular cage and $60 \%$ in the rectangular one. In the second set with 10 crickets, $40 \%$ and $60 \%$ survived in the circular and rectangular cage, respectively. It seems that the density of the crickets in the cages did not affect the mortality. The circular cage appears to be more suitable for oviposition and the rectangular for nymphs later than the $3^{\text {rd }}$ instar for better survivability.

\section{Acknowledgment}

This study was supported by the Agenda Rrogram(Grant no. PJ0075362012) of the Rural Development Administration(RDA), Republic of Korea. We are grateful for ILSoon Jeong and Ok-Soon Han who helped us out with all the rearing and experiment. Also special thanks go to IlKwon Kim (Korea National Arboretum) for proofreading.

\section{Reference}

Bang HS, Kim MH, Jung MP, M. S. MS, Na YE, Kang KK, 
Lee DB, Lee KY (2009) Effects of chilling and Overwintering Temperature Conditions on the Termination of Egg Diapause of the Ussur Brown Katydid Paratlanticus ussuriensis. Korean J Appl Entomol 48(2), 221-227.

Choi J, Ahn My, Lee YB, Ryu KS (2002) Insect crude drugs. Shinil pp 32.

Heo JC, Lee DY, Son MS, Yun CY, Hwang JS, Kang SW, Kim EH, Lee SH (2008) Effects of Mole Crickets(Gryllotalpa orientalis) Extracts on Anti-oxidant and Anti-inflammatory Activities. Journal of Life Science 18(4), 509-514.

Kim KW, Kim SS, Son JS (1989) The Oviposition Period, Emergence Period, and Flight Activity of the African Mole Cricket(Gryllotalpa africana Palisot de Beauvois) Adult Damaging Ginseng Plants. Korean J Ginseng Sci 13(1), 119122.

Kim KW (1993) Phonotaxis of the African Mole Cricket, Gryllotalpa africana Palisot de Beauvois. Korean J Appl
Entomol 32(1), 76-82

Kim KW (1995) Seasonal Changes in Age Structure and Fecundity of the African Mole Cricket (Gryllotalpa africana) Population in Suwon, Korea. Korean J Appl Entomol 34(1), 70-74.

Kim NJ, Hong SJ, Seol KY, Kwon OS, Kim SH (2005) Eggforming and Preservation Methods of the Emma Field Cricket Eggs, Teleogryllus emma(Orthoptera: Gryllidae). Korean J Appl Entomol 44(1), 61-65.

Lee GE (2008) Comparative Efficiency of Artificial Diets on the Developmental Stages of Gryllotalpa orientalis Burmeister (Orthoptera: Gryllotalpidae), pp. 1 25, Master dissertation, Cheju National University, Korea.

Park HY (2005) Successful examples of development of beneficial insect resource for human life, pp. 28 30, KSBB, Proceeding of Current Biotechnology and Bioengineering (XVII). 